Artigo

\title{
A produção de conhecimentos sobre Educação Superior no Brasil em artigos publicados entre 2008 e 2018
}

\author{
Artur Jacobus \\ Ricardo Ferreira Vitelli \\ Rosangela Fritsch \\ Universidade do Vale do Rio dos Sinos (Brasil)
}

\section{Resumo}

$\bigcirc$ presente artigo tem o objetivo de oferecer uma síntese analítica das produções acadêmicas sobre o panorama atual da educação superior brasileira. $\bigcirc$ estudo tem caráter exploratório descritivo, utilizando a pesquisa bibliográfica. $\bigcirc$ material empírico se constituiu de 130 artigos publicados entre 2008 e 2018 em periódicos captados no Portal de Periódicos CAPES que apresentam um panorama do ensino superior brasileiro contemporâneo, tratando de tendências, políticas, modelos e configurações de gestão. Resultou em dois tipos de análises: bibliométrica e reflexiva/interpretativa. Os resultados indicam forte concentração de publicações entre 2015 e 2017, com foco principal em instituições privadas. Os estudos foram classificados em nove macrocategorias: políticas educacionais, expansão, internacionalização, diversificação, avaliação do ensino superior, gestão universitária, mercantilização, democratização e inclusão. Como tendência, percebeu-se que o cenário da educação superior no Brasil é fortemente influenciado por movimentos globais do capitalismo com viés neoliberal, com incentivo de organismos multilaterais que impulsionam uma expansão mercantilizada, diversificada, privada e elitizada.

Palavras-chave: Educação superior. Brasil. Produção de conhecimentos. Políticas educacionais.

\section{The production of knowledge on Higher Education in Brazil in articles published between 2008 and 2018}

\begin{abstract}
The present article has the objective of offering an analytical synthesis of academic productions on the current panorama of Brazilian higher education. The study has a descriptive exploratory purpose, using bibliographic research. The empirical material consisted of 130 articles published between 2008 and 2018 in journals captured in the Portal of CAPES Journals that present a panorama of the contemporary Brazilian higher education, dealing with trends, policies, models and management configurations. It resulted in two types of analysis: bibliometric and reflective/ interpretive. The outcomes indicate a strong concentration of publications between 2015 and 2017 , with a focus on private institutions. The studies were classified into nine major categories: educational policies, expansion, internationalization, diversification, evaluation of higher education, university management, commercialization, democratization and inclusion. As a trend, it was noticed that the scenario of higher education in Brazil is strongly influenced by global movements
\end{abstract}


A produção de conhecimentos sobre Educação Superior no Brasil em artigos publicados entre 2008 e 2018

of capitalism with neoliberal bias, with the encouragement of multilateral organizations that promote a commercialized, diversified, private and elitist expansion

Keywords: Higher Education. Brazil. Production of knowledge. Educational policies.

\section{La producción de conocimientos sobre Educación Superior en Brasil en artículos publicados entre 2008 y 2018}

\section{Resumen}

El presente artículo tiene el objetivo de ofrecer una síntesis analítica de las producciones académicas sobre el panorama contemporáneo de la educación superior de Brasil. El estudio tiene carácter exploratorio descriptivo, utilizando la investigación bibliográfica. El material empírico se constituyó de 130 artículos publicados entre 2008 y 2018 en periódicos captados en el Portal de Periódicos CAPES que presentan un panorama de la enseñanza superior brasileña contemporánea, tratando de tendencias, políticas, modelos y configuraciones de gestión. Resultó en dos tipos de análisis: bibliométrica y reflexiva/interpretativa. Los resultados indican una fuerte concentración de publicaciones entre 2015 y 2017 , con foco principal en instituciones privadas. Los estudios se clasificaron en nueve macro categorías: políticas educativas, expansión, internacionalización, diversificación, evaluación de la enseñanza superior, gestión universitaria, mercantilización, democratización e inclusión. Como tendencia, se percibió que 2 el escenario de educación superior en Brasil es fuertemente influenciado por movimientos globales del capitalismo con sesgo neoliberal, con incentivo de organismos multilaterales que impulsan una expansión mercantilizada, diversificada, privada y elitizada.

Palabras clave: Educación superior. Brasil. Producción de conocimientos. Políticas educativas.

\section{Introdução}

O objetivo principal deste estudo foi analisar a produção de conhecimentos sobre a educação superior no Brasil no período entre 2008 e 2018. Entende-se que, frente a um cenário complexo e dinâmico, torna-se necessário um estudo que ofereça uma síntese analítica das produções acadêmicas sobre o panorama atual da educação superior brasileira, permitindo-se, assim, que se alcance uma visão integradora de suas temáticas, abordagens, convergências e divergências, bem como das perspectivas que se abrem para novas investigações.

Para fins de contextualização, sublinha-se que a compreensão do cenário ałual da educação superior brasileira deve levar em conta as concepções e modelos de universidade, assim como os interesses e tendências 
em debate na atualidade. Em artigo publicado, Pereira (2009) analisa o surgimento da universidade denominada "moderna", as funções e papéis a ela atribuídos ou dela esperados, a crise desse modelo nos tempos atuais e alguns dos elementos que caracterizam a universidade contemporânea. Para a autora, a instituição que se constituiu como "universidade moderna" teve origem na organização da Universidade de Berlim, em 1808. Assim, passados dois séculos, afirma que os pressupostos de Humboldt de promoção do desenvolvimento máximo da ciência e formação intelectual e moral da nação são ainda relevantes. No entanto, percebe que várias de suas premissas têm sido negligenciadas ou substituídas por outras menos nobres. É o caso dos princípios de formação através da pesquisa, da unidade entre o ensino e pesquisa, da interdisciplinaridade, da autonomia e a liberdade da administração da instituição e da ciência que produz, da relação integrada, porém autônoma, entre Estado e Universidade, da complementaridade do ensino fundamental e médio com o universitário. Conclui que, na atualidade, em um período denominado pós-moderno, a universidade moderna está em crise com a discussão um novo projeto para a instituição.

Destacamos a contribuição de Dias Sobrinho (2014; 2015) com o debate sobre a universidade contemporânea, problematizando o capitalismo acadêmico e discute a ideia de uma universidade fraturada. Para Dias Sobrinho (2014), por inserir-se na sociedade global, a universidade valoriza, prevalentemente, o capitalismo acadêmico próprio de uma economia do conhecimento. Contudo, para o autor, a universidade atual também tem incomensuráveis possibilidades de contribuir para os processos de construção de uma sociedade democrática do conhecimento e de recuperar sua missão histórica no processo civilizatório. Dias Sobrinho (2015) considera que a educação e o conhecimento são bens públicos e direitos humanos essenciais, devendo apresentar qualidade com sentido científico e social. A universidade fraturada, como é apresentada pelo autor, representa a crítica à lógica neoliberal e mercadológica de um projeto elitista, pragmático e utilitarista, em que o direito humano é negligenciado. Para o autor, qualidade apenas para o mercado é a redução do cidadão ao capital ou recurso humano.

Dias Sobrinho (2015) explicita duas concepções contraditórias da universidade na contemporaneidade: a universidade como instituição de formação humana integrada a projetos civilizacionais, ou como instância a serviço do mercado e dos interesses privados dos indivíduos. 
Imersa nesse contexto de crise e de embate de concepções contraditórias, a educação superior brasileira tem sido objeto de diversos estudos.

Selecionando um período de dez anos de produções acadêmicas, busca-se entender os cenários da educação superior brasileira, perspectivas que se vislumbram e fatores que são intervenientes nas configurações das instituições superiores de ensino. Ao final do artigo, constituímos grupos de percepções diferentes, alinhadas a fatores de diferentes interesses de grupos que atuam na formação de políticas para a educação superior brasileira. Com isso, a análise desenvolvida no artigo oferece uma síntese analítica das produções acadêmicas sobre o panorama atual da educação superior brasileira, suas caminhadas, seus protagonistas e a arena de forças da agenda de políticas nesta etapa do campo educacional.

Na sequência, após a descrição metodológica, será apresentada uma síntese integradora desses estudos, procurando-se identificar e analisar as convergências e divergências de suas temáticas e abordagens.

\section{Descrição Metodológica}

Este estudo tem caráter exploratório descritivo, utilizando-se a pesquisa bibliográfica como procedimento metodológico (PIZZANI, SILVA, BELLO, HAYASHI, 2012; LIMA, MIOTO, 2007). Alinha-se à ideia de que a revisão de literatura é uma etapa que integra todas as pesquisas, enquanto a pesquisa bibliográfica "[...] implica um conjunto ordenado de procedimentos de busca por soluções, atento ao objeto de estudo, e que, por isso, não pode ser aleatório" (LIMA; MIOTO, 2007, p. 38).

$\mathrm{Na}$ etapa de levantamento do material bibliográfico, inicialmente, foram definidas bases de consulta e parâmetros para mapeamento das pesquisas: a) parâmetros temáticos: perfil das instituições de ensino superior, cenário atual, tendências, políticas, modelos e configurações de gestão, descartando-se estudos de casos; bl parâmetro linguístico: português; c) fonte: artigos científicos publicados em periódicos brasileiros disponíveis na base de dados do Portal de Periódicos da Coordenação de Aperfeiçoamento de Pessoal de Nivel Superior (CAPES); d) parâmetro cronológico de publicação: artigos publicados entre 1\%1/2008 até 30/06/2018; el descritores: sintagmas 
"Educação Superior" OR "Ensino Superior". O levantamento do material bibliográfico ocorreu em julho de 2018.

A busca na base de dados resultou em 887 artigos, cujos resumos foram submetidos a critérios temáticos de análise. Foram descartados estudos de caso, selecionando-se apenas aqueles que apresentassem um panorama do ensino superior brasileiro contemporâneo, tratando de tendências, políticas, modelos e configurações de gestão. $\bigcirc$ emprego desses critérios produziu um saldo de 130 artigos.

A etapa de análise desdobrou-se em três processos estruturantes: a organização e a leitura de reconhecimento do material bibliográfico, a análise bibliométrica e a análise reflexiva e interpretativa.

Na análise bibliométrica, os artigos foram classificados quanto ao ano de publicação, à categoria administrativa enfocada (pública, privada ou ambas), temas de estudo a partir das palavras chaves, periódicos e autores com maior produção no campo e perspectivas teórico-metodológicas.

Para análise qualitativa, foram atribuídas de uma a três palavras-chave para cada documento, tendo por base uma apreciação das palavras-chave originais, o resumo do artigo, bem como seus objetivos e resultados. Nesse processo, ao todo, foram geradas 48 categorias de análise, que, em função de sua afinidade temática, foram agrupadas pelos pesquisadores em nove macrocategorias de análise: políticas educacionais, expansão, internacionalização, diversificação, avaliação do ensino superior, gestão universitária, mercantilização, democratização e inclusão.

Dessa forma, a cada um dos 130 artigos foi associada de uma a três dessas macrocategorias, pois entendeu-se que estas não são dicotômicas, podendo ser simultaneamente aplicadas a um mesmo texto. Por fim, os artigos agrupados nessas macrocategorias foram lidos na íntegra e então analisados considerando suas convergências e divergências e seus achados.

\section{Sumarização e análise bibliométrica}

Nesta etapa, apresentamos as quantificações de alguns dados apreendidos dos artigos selecionados. No Gráfico 1, aparecem os períodos e as quantidades de artigos presentes no estudo. Conforme pode ser visualizado no gráfico 1, constatou-se grande concentração de artigos sobre o ensino superior 
brasileiro contemporâneo publicados no período de 2015 a 2017 (62 artigos), correspondendo a 47,69\% do total final de artigos. Cabe destacar que o ano de 2018 não havia sido concluído por ocasião do encerramento do estudo.

\section{Gráfico 1}

Distribuição dos artigos selecionados no estudo no período de 2008-2018

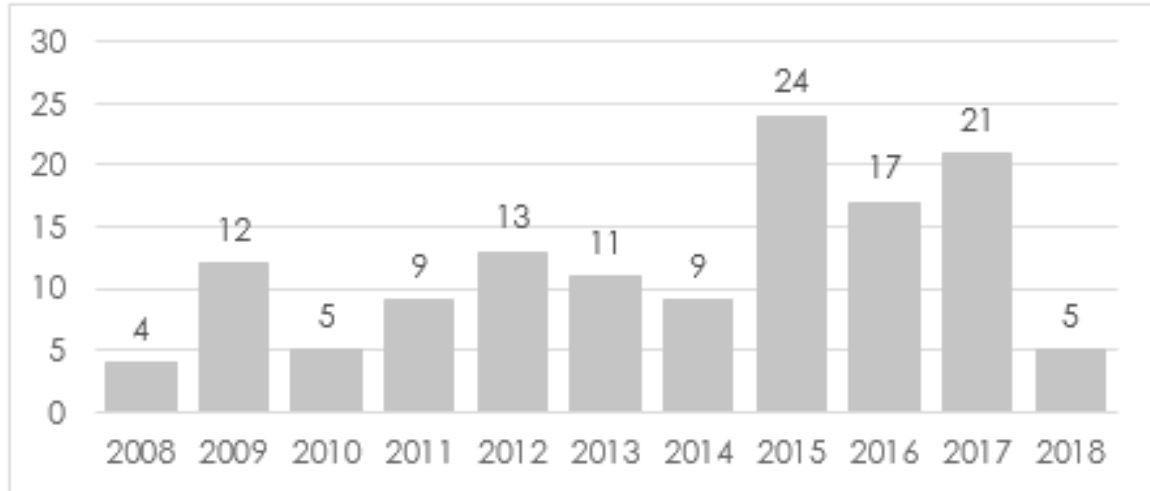

Fonte: elaborado pelos autores.

No gráfico 2, os artigos foram classificados em função dos tipos de Instituições de Ensino Superior (IES) que foram objetos das pesquisas. Três agrupamentos foram definidos: públicas, particulares e públicas/privadas. A maior parte dos estudos se referem a IES Privadas $(69,53 \%)$, seguindo-se as IES Públicas (19,53\%). Também havia estudos em que a abordagem se deu a partir da comparação entre IES Públicas e Privadas (10,94\%). 


\section{Gráfico 2}

Distribuição da amostra de artigos por tipo de IES I

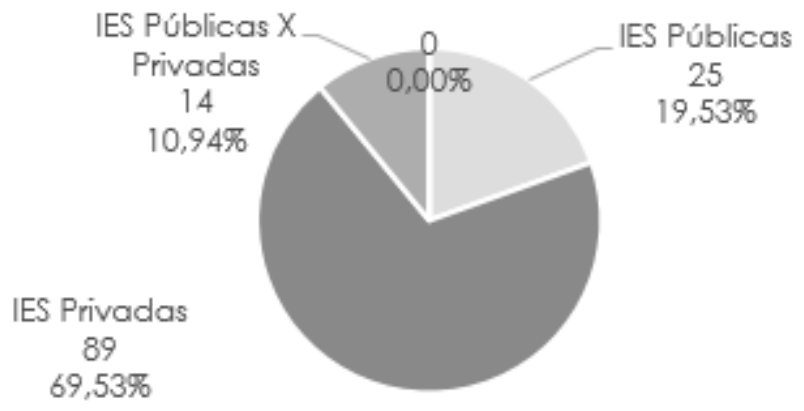

Fonte: elaborado pelos autores.

No gráfico 3, são apresentados os temas definidos pelos autores do estudo a partir das palavras chaves. Foram identificados 14 temas, sendo que a maior parte dos artigos teve foco em políticas educacionais e diversificação.

\section{Gráfico 3}

Agrupamento dos temas por palavras-chave

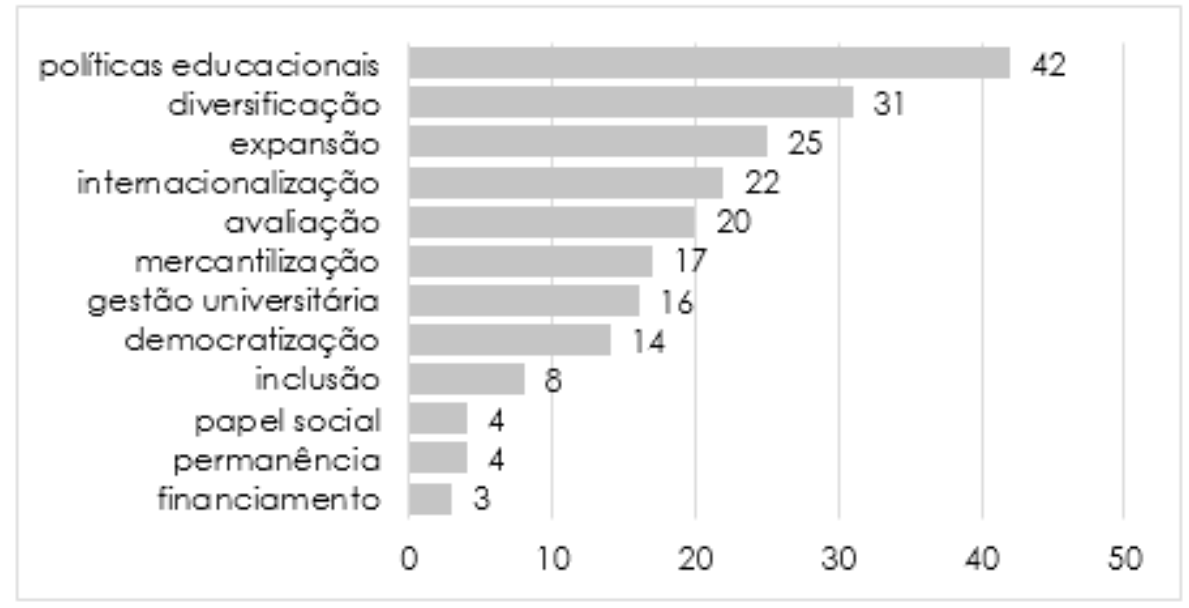

Fonte: elaborado pelos autores. 
Os resultados de perfil dos artigos selecionados indicam que os temas abordados se concentraram, principalmente, no período de tempo de 2015 até 2017, ou seja, a temática do ensino superior é uma tendência que se encontra presente em estudos mais recentes, tendo se acentuado nos últimos três anos.

Os periódicos com maior concentração de publicações têm como escopo a educação superior: Revista Internacional de Educação Superior e Avaliação: Avaliação da Educação Superior (com 18 artigos em cada uma delas). Registra-se que na Revista Educação em Questão foram selecionados 12 artigos, na Revista Histedbr On-line, 7 artigos e na Revista Educação e Sociedade, 6 artigos.

Com relação à autoria dos artigos selecionados, constatou-se uma pulverização de autores, mas alguns aparecem mais frequentemente. Por exemplo: José Dias Sobrinho e Alisson Slider do Nascimento de Paula aparecem com quatro artigos publicados; Diego Bechi, com três; Pricila Kohls dos Santos, Marília Costa Morosini e Cristina Helena Almeida de Carvalho, com dois. Os demais apareceram com participação em um artigo.

Em termos de perspectivas teórico-metodológicas, as pesquisas são majoritariamente qualitativas e configuradas como pesquisas bibliográficas, revisões de literatura, estado da arte e documentais. Parte destas, de forma complementar, utilizam dados e indicadores quantitativos a partir de bases de dados oficiais: Instituto Nacional de Estudos e Pesquisas Educacionais Anísio Teixeira (INEP), Ministério da Educação (MEC), Instituto Brasileiro de Geografia e Estatística (IBGE), Programa das Nações Unidas para o Desenvolvimento (PNUD). Poucas pesquisas expressam a sua orientação em relação ao método de análise e, quando explicitam sua escolha, é pelo materialismo dialético. Verifica-se uma lacuna em relação à inspiração em perspectivas teóricas claramente definidas e estudos comparados. Além disso, constatou-se limitado uso de entrevistas e questionários como procedimentos de produção de dados.

\section{Resultados qualitativos}

A análise qualitativa, a seguir apresentada, foi organizada a partir das nove macrocategorias de análise temáticas identificadas no conjunto de 130 artigos. 
Políticas educacionais

Entre os temas abordados no conjunto de artigos selecionados, o tópico mais recorrente foi o que se refere a políticas educacionais (42 artigos). Esse assunto foi abordado sob os mais diferentes focos de investigação. Foram identificados 22 focos, rearranjados posteriormente em subcategorias de análise. No quadro 1 são descritos os temas e subtemas encontrados nesses 42 artigos.

\section{Quadro 1}

\section{Subgrupos de análise em função da proximidade dos focos de abordagem}

\begin{tabular}{|l|l|}
\hline \multicolumn{1}{|c|}{ Subgrupos } & \multicolumn{1}{c|}{ Focos } \\
\hline $\begin{array}{l}\text { Políticas de interesse político } \\
\text { e econômico }\end{array}$ & $\begin{array}{l}\text { Neoliberalismo/neoinstitucionalismo/Banco } \\
\text { Mundial/organismos multilaterais/de governo/ } \\
\text { década de 1990/avaliação/internacionalização }\end{array}$ \\
\hline Políticas de expansão & Expansão/Reuni/acesso/IFEs/EaD \\
\hline Políticas de democratização & $\begin{array}{l}\text { Perman ên cia/i n clus ã o/ProUni/Fies / } \\
\text { democratização/financiamento }\end{array}$ \\
\hline $\begin{array}{l}\text { Políticas de planejamento } \\
\text { educacional }\end{array}$ & PNE/PDE/LDB \\
\hline
\end{tabular}

Fonte: elaborado pelos autores.

A necessidade de investimentos em inovação e a ideia de aderir à concepção da sociedade do conhecimento foram dois aspectos citados com pouca incidência e não aparecem no quadro.

Na subcategoria das políticas educacionais de interesse político e econômico, inserem-se artigos que tratam da interferência de modelos econômicos, de interesses de atores externos ao campo educacional, de cunho partidário (de governo), de avaliação da educação superior, principalmente, tendo como foco as consequências das políticas adotadas a partir da década de 1990. Alguns autores presentes nos artigos selecionados dentro deste subgrupo são Morosini e Corte (2018); Dias Sobrinho e Brito (2008), Lima, Azevedo e Catani (2008); e Paula, Costa e Lima (2018).

Dias Sobrinho e Brito (2008) destacam a atuação de organismos multilaterais na formação das políticas públicas educacionais no Brasil e na América Latina, o que, de modo geral, envolve a "recomendação" de que 
esses Estados promovam a privatização da educação superior, prática que se relaciona com o ideário neoliberal de Estado mínimo.

Organismos como o Banco Mundial, o Fundo Monetário Internacional (FMI) e a Organização para a Cooperação e Desenvolvimento Econômico (OCDE), em seus documentos e recomendações, indicam um conjunto de ações que servem como uma "cartilha" para os Estados latino-americanos, muitas vezes assumindo a forma de condições para a liberação de financiamentos. A implementação dessas recomendações tende a trazer consequências negativas para o sistema educacional superior brasileiro, como a privatização e a adaptação da universidade aos interesses de grupos empresariais.

Já os artigos que tratam das políticas de expansão da educação superior brasileira tratam de temas como o Programa de Apoio a Planos de Reestruturação e Expansão das Universidades Federais (Reuni), Financiamento Estudantil (Fies), Ensino a Distância (EaD) e políticas de acesso objetivando a expansão do sistema. Nesse grupo, destacam-se os trabalhos de Fávero e Sguissardi (20 12); Melo, Melo e Nunes (2009) e Maués e Souza (20 18 ).

Nesse subgrupo de análise, o Programa Reuni, entre os temas presentes nesse subgrupo de análise, presente nos artigos de Borges e Aquino (2012) e Melo, Melo e Nunes (2009), apresentam algumas constatações que apontam para a ideia de que, apesar do aumento de ofertas de cursos e vagas, o programa não garantiu o aumento do número de matrículas principalmente em função das taxas de evasão, que não foram combatidas.

Já o Fies é apresentado como um programa de financiamento da educação superior em conformidade com as recomendações de organizações multilaterais. Azevedo (2015) destaca a ideia de que seu funcionamento é interpretado como uma forma de dar incremento à participação de matrículas em instituições privadas.

Em relação às políticas de expansão, os artigos tratam também de políticas afirmativas e da necessidade de expansão associada à qualidade. (MELO; MELO; NUNES, 2009). A modalidade EaD é vista como uma possibilidade de maior acesso a estudantes no nível superior, principalmente, em localidades sem a oferta desse tipo de educação.

No campo das políticas visando à democratização, foram incluídos os temas que abordaram as políticas de permanência, inclusão, Programa Universidade para Todos (ProUni) e Fies. As políticas de permanência e inclusão 
são correlacionadas às propostas especificadas pelo ProUni e Fies. Chaves e Amaral (2015); Gomes e Moraes (2012), Silva, Amauro, Souza e Rodrigues Filho (2017) estão entre os autores com estudos sobre o tema.

Os estudos englobados nesta categoria revelam que a forma como foram geridas as políticas de permanência (com o Fies) e de inclusão (com o ProUni) geraram problemas que agora se agravam com a redução ou quase eliminação das verbas, especialmente para o Fies. Na dependência dos estudantes de um financiamento para seguirem seus estudos, o Estado se desvincula de uma proposta de ensino superior gratuita. Até mesmo a inclusão por meio do ProUni está vinculada à ideia de que o Estado reforce as vagas no ensino superior privado, em detrimento do público. Outra crítica feita à ampliação da oferta, pela "democratização" do acesso, é que ela atende a interesses empresariais na formação de mão de obra que atenda a suas necessidades. Esse contingente maior de estudantes, em um processo de educação de massa, fez com que as IESs acrescentassem às suas ofertas a possibilidade de uma formação com oferta de cursos técnicos.

Já os artigos que se dedicam às políticas de planejamento educacional estudam os planos governamentais para a educação como o Plano Nacional de Educação (PNE) e o Plano de Desenvolvimento da Escola (PDE) ou ainda a Lei de Diretrizes e Bases da Educação (LDB) - Lei no 9.394, de 20 de dezembro de 1996 -, que foi o marco que definiu a construção das políticas educacionais, ainda que sua efetivação seja dominada pela égide do ideário neoliberal. A ideia do Estado elaborar planos educacionais é apresentada como uma concepção positiva, no sentido de não se basear em políticas de governos, mas sim em políticas de longo prazo. No entanto, a constituição dessas políticas acaba sendo afetada por um conjunto de atores, com os mais diversos tipos de interesses, muitas vezes conflitantes com as concepções de atores do campo educacional (UUNG, CAUDURO, SUDBRACK, 2016; PAULA, LIMA, LIMA, COSTA, 2017; MINTO, 2018).

Conforme Queiroz, Queiroz, Vasconcelos, Furukava, Hékis e Pereira (2013), a partir da década de 1990, a constituição das políticas públicas educacionais deixou de ter um caráter de interesse público no atendimento da sociedade pela demanda por educação.

PDE e o PNE surgem em períodos de franca ascensão das políticas neoliberais no Brasil. Dessa forma, o planejamento da educação, tanto 
A produção de conhecimentos sobre Educação Superior no Brasil em artigos publicados entre 2008 e 2018

superior, quanto nos demais níveis, segue premissas como a do Estado mínimo; desmassificação da educação e da concepção de que a educação é um bem a ser comercializado.

Diversificação

A macrocategoria da diversificação foi recorrente nos textos analisados, presente em 31 artigos. Nesta pesquisa, essa categoria mais geral engloba, além da diversificação, temas como a educação a distância, as distinções, semelhanças e complementaridades entre instituições de ensino superior públicas e privadas, bem como a distinção entre instituições privadas com e sem fins lucrativos. Os artigos analisados apresentam notável convergência na identificação dos princípios que têm norteado a diversificação do ensino superior brasileiro. $\bigcirc$ crescimento da participação de instituições privadas, focadas no ensino, em detrimento da pesquisa, a opção pela educação a distância, a oferta de cursos de curta duração e com foco profissionalizante são interpretados como movimentos que buscam adaptar o ensino superior às necessidades de um projeto capitalista neoliberal (SEVERINO, 2008; SILVA, 12 2015; MINTO, 2018).

Em diversos artigos, documentos produzidos pela Organização das Nações Unidas para a Educação, a Ciência e a Cultura (Unesco) e Banco Mundial são identificados como a materialização dos planos que visam tornar a educação em nível superior como um meio para formar capital humano conforme as demandas empresariais. Sob essa lógica, a desejada massificação da educação terciária implicaria um abandono do modelo de universidade centrado na pesquisa e da perspectiva de formação para a cidadania (SEVERINO, 2008; SAMPAIO, 2014). Ao mesmo tempo, artigos analisados apontam que 0 modelo de diversificação adotado pelos governos brasileiros a partir dos anos 1990 favorece grandes grupos privados, que adquirem ganhos de escala com a aquisição de instituições menores e com a disseminação da educação a distância (PIMENTA, 2017).

Os estudos sobre a diversificação do ensino superior tratam mais da opção brasileira pelo massivo uso da educação a distância e pela coexistência de poucas instituições dedicadas à pesquisa (majoritariamente públicas), comum a ampla maioria de instituições focadas no ensino (faculdades, centros 
universitários, institutos e centros de educação tecnológica). Pouco destaque é dado para as diferentes formas de curso superior, como a graduação tecnológica, por exemplo. (SEGENREICH; CASTANHEIRA, 2009).

Em relação à diversificação por meio da educação a distância, percebe-se, nos estudos que tratam desse tema, que o ensino não presencial é uma opção que não pode ser desconsiderada pelo País, viabilizada pelo desenvolvimento de novas tecnologias da comunicação e da informação. Porém, são recorrentes as críticas ao fato de que a educação a distância no Brasil tornou-se uma mercadoria que produz grandes lucros para grupos empresariais privados, sem que o governo e a sociedade possam garantir sua qualidade (ALONSO, 2010; PIMENTA, 2017). A esse propósito, o processo de diversificação adotado no Brasil nas últimas três décadas é visto como resultado de pressões desses grupos, com prejuízo para as instituições privadas sem fins lucrativos e, especialmente, para as instituições públicas, que não recebem investimentos suficientes para atender à crescente demanda por formação de nivel superior.

Expansão

Foram analisadas 25 produções que tiveram a expansão da educação superior como objeto de estudo. Encontrou-se convergência dos autores na constatação de que a expansão da educação superior no Brasil, nas últimas décadas, é fato incontestável e decorrência de um projeto neoliberal combinado com uma crise estrutural do capitalismo e como uma configuração de Estado mínimo e avaliador. Como consequência, essa expansão é de natureza mercantil, privatizante, massificada e pautada por princípios de desregulamentação, diversificação e flexibilização (LIMA FILHO, 2015).

Pesquisas recentes têm acentuado que acrescenta-se à privatização um processo de oligopolização, que acelera o acesso da classe trabalhadora pela massificação e mensalidades baixas, com predominância da iniciativa privada, num movimento que revela "[...] a mão bastante visível do Estado, dela emergindo um 'quase mercado' [...]". (MARQUES, 2013, p. 81).

A educação a distância é tratada como uma estratégia de expansão que se articula com os elementos já anunciados e é "[...] claramente tomada 
como modalidade de ensino para aceleração rápida da expansão de vagas no ensino superior" (ALONSO, 2010, p. 1.320).

Em termos de recortes principais, sobressaíram-se pesquisas que tratam das influências de organismos internacionais (OCDE, Banco Mundial), de modelos inspirados pela Declaração de Bolonha e de modelos americanos; privatização; EaD; políticas públicas de governos específicos, PNE, ProUni, Fies, Reuni, Universidade Aberta do Brasil (UAB); e da relação qualidade versus quantidade e massificação. Identificou-se pouca incidência de estudos sobre a reconfiguração territorial do ensino superior brasileiro, desenvolvimento, financiamento e trabalho docente e adoecimento. Como lacuna, registra-se a ausência de estudos sobre a pós-graduação lato e stricto sensu.

\section{Avaliação do Ensino Superior}

Dos 130 artigos analisados, 20 exploram o macrotema da avaliação, englobando subtemas como qualidade, ranqueamento, o sistema de avaliação do ensino superior adotado no Brasil, o SINAES, e, mais recentemente, os 14 processos de acreditação de cursos e instituições. Ainda que se perceba nos estudos uma unanimidade quanto à importância dos processos avaliativos, encontram-se posições divergentes em relação ao modelo de avaliação a que o ensino superior brasileiro tem sido submetido. A raiz dessa divergência situa-se em concepções diferentes sobre o que é a qualidade e sobre a quem devem servir as universidades. Predomina nos estudos uma apreciação crítica em relação às políticas de avaliação das instituições de ensino superior brasileiras, entendendo-se que elas, de forma geral, subordinam-se a uma concepção de qualidade total, tipicamente adotada no meio empresarial. A essa visão utilitarista, contrapõem-se os conceitos de qualidade social (COSTA; COSTA E SILVA, 2015) e da qualidade na perspectiva da equidade (MOROSINI, 20 14), que priorizam a contribuição do ensino superior para a formação da cidadania e não para a acumulação do capital. Ainda assim, alguns estudos, apesar de ressalvas enunciadas quanto às limitações do SINAES, valem-se dos resultados desse sistema de avaliação externa para mostrar, por exemplo, a superioridade das universidades públicas em relação às privadas (HOFFMANN; ZANINI; CORRÊA; SILUK; SCHUCH JÚNIOR; ÁVILA, 2014). 
Uma das principais críticas encontradas nos estudos dedicados à avaliação tem como alvo o ranqueamento das instituições a partir de seus resultados nos processos seletivos externos. A classificação que anualmente é apresentada à sociedade reforça uma ideia simplista de que se pode avaliar a qualidade dos cursos e das instituições dando ênfase ao desempenho dos estudantes em exames como o Exame Nacional de Desempenho dos Estudantes (Enade), deixando em segundo plano outras variáveis (PAULA, COSTA e LIMA, 20181 .A esse respeito, há autores que apontam para temas de investigação a respeito do ranqueamento:

Quais dimensões dos rankings podem ser direcionadas para mensuração da qualidade do ensino nas universidades e não apenas para construção de reputação sob a égide do mercado? $\bigcirc$ sistema de ranqueamento descreve reputação ou constrói e vende reputação? (MOURA; MOURA, 2013, p. 221).

Ainda no campo da avaliação do ensino superior, percebe-se a emergência de temas ainda pouco explorados, vinculados normalmente a processos de internacionalização, como o da acreditação (LIMA; AZEVEDO; CATANI, 2008) e das certificações de garantia de qualidade (MOROSINI, 20 14).

\section{Mercantilização}

Processo de mercantilização, observado em 17 artigos analisados, passa por três aspectos que foram agrupados em: políticas públicas, pressão de organismos multilaterais e o ideário neoliberal. As políticas públicas educacionais do Estado brasileiro contribuíram para que as instituições privadas passassem a ter uma crescente participação na quantidade de matrículas do ensino superior. Esse fato ocorreria em função de o Estado brasileiro não sustentar um atendimento satisfatório das crescentes demandas na educação superior.

Com relação às políticas públicas que conduzem à mercantilização do ensino superior brasileiro, destacamos a constituição de parcerias público-privadas (PPP); a adoção de indicadores educacionais para mensurar a qualidade da educação, estimulando a competição; a performatividade, a elaboração de rankings por meio de indicadores. Dessa forma, o Estado intencionalmente não apenas cria uma competição entre instituições de ensino, como também acirra a comparação entre instituições públicas e privadas. 
A produção de conhecimentos sobre Educação Superior no Brasil em artigos publicados entre 2008 e 2018

Outro aspecto mencionado nos artigos como sustentador da mercantilização são as pressões de organismos multilaterais. Em estudos como de Fávero e Bechi (2017), esses organismos reforçam a ideia de que as universidades públicas precisam seguir um modelo de gestão de instituições privadas, com indicadores de desempenho, como forma de mostrar a eficiência maior da gestão privada, em detrimento da pública. Os organismos multilaterais contribuem também com a entrada de capital internacional na educação superior, expandindo a educação privada e também favorecendo a criação de oligopólios educacionais, pois a educação superior é vista como uma "mercadoria" que pode ser comercializada de forma lucrativa.

O processo de mercantilização também alcança os cursos de graduação, aproximando seus currículos às necessidades do mercado de trabalho, e tornando os cursos "reféns" do mercado. Nesse sentido, o conhecimento passa a ser um "produto" a ser comercializado. Essa lógica acaba privilegiando mais cursos/áreas de cunho tecnológico do que humano. No contexto educacional observado nos estudos, entram ainda os processos de globalização, que massificam as universidades, concebendo-as como modelos padronizados e passíveis de serem compartilhados entre estudantes de diferentes países.

Gestão universitária

Na macrocategoria da gestão universitária, encontram-se 13 artigos que tratam da gestão das instituições de ensino superior, com ênfase em temas como a autonomia universitária, gestão democrática e os desdobramentos para a gestão das instituições de um fenômeno mais amplo, referenciado como a "crise das universidades". Apesar da ênfase conferida pelos pesquisadores mais a um ou outro desses temas, os artigos tendem a se integrar, pois a crise vivida pelas universidades, especialmente as públicas, é relacionada a uma perda de autonomia devido à diminuição de investimentos estatais e pela pressão externa que sofrem as instituições universitárias para que assumam uma postura pragmática, submetendo-se às demandas empresariais (DIAS; SERAFIM, 2015; AGUIAR, 2016). Um receio presente em alguns desses estudos diz respeito à potencial incompatibilidade entre a priorização da relação de quase-mercado no âmbito das universidades públicas e o cumprimento da sua função social, como a formação para a cidadania (CASTRO; PEREIRA, 2014). Um tema a ser mais explorado diz respeito à capacidade das instituições de 
ensino superior de resistirem ou se adaptarem às influências externas, tanto governamentais como do mercado, e o efeito dessa tensão ou adaptação sobre sua missão civilizatória.

Internacionalização

A internacionalização é situada no contexto da globalização dos mercados e abertura das fronteiras comerciais e do capitalismo cognitivo, em que o conhecimento ganha centralidade por ser reconhecido como a principal força produtiva. Na sociedade globalizada, o conhecimento tornou-se um poderoso ingrediente para o desenvolvimento sustentável dos países e, num contexto de transformações, mediante os pilares da sociedade do conhecimento, as universidades têm investido em processos de internacionalização, ultrapassando suas fronteiras, tornando-se peça chave na dinâmica de cooperação e produção entre as nações e seus respectivos mercados (MOROSINI; CORTE, 2018).

Foram analisadas 12 produções sobre o tema da internacionalização. As temáticas abordadas são: o Processo de Bolonha e as consequências e impactos para o Brasil; cenários, tendências e políticas nacionais de internacionalização, especialmente com foco na pós-graduação; gestão universitária e perfil de gestões, estratégias de internacionalização e relação com a qualidade da educação.

A internacionalização evidencia-se como meta da Declaração de Bolonha e da consolidação da Área Europeia de Ensino Superior (AEES), de viés mercadológico, com a interferência direta do mundo dos negócios na forma de organização e funcionamento da universidade. Por sua vez, o Processo de Bolonha busca resgatar, pelo viés da Europa do conhecimento, a racionalidade eurocêntrica. "Concretamente, os impactos de Bolonha já são visíveis no espaço da educação superior brasileira, ainda que, muitas vezes, carecendo de debate e explicitação" (WIELEWICKI; OLIVEIRA, 2010, p. 228).

Dentre as estratégias para a internacionalização, destaca-se a mobilidade acadêmica. Atualmente, na perspectiva de políticas e gestão universitária, a internacionalização é uma das prioridades das IES, porém o 
[...] caso brasileiro se encaixa, de forma geral, na atuação passiva, devido à ausência de infraestrutura e de políitcas que atraiam pesquisadores estrangeiros, uma vez que as ações são focadas na mobilidade out de forma puramente reativa (FRANKLIN; ZUIN; EMMENDOERFER, 2018, p. 140).

No debate conceitual entre democratização e qualidade da educação, a internacionalização parece apontar para exigências meritocráticas, envolvendo carreiras de complexidade mais alta, trajetórias estudantis com maiores oportunidades culturais, incluindo o domínio de idiomas e disponibilidade de condições para afastar-se do trabalho, entre outras condições. (CUNHA, 2017).

\section{Inclusão}

Na categoria da inclusão, foram analisadas dez pesquisas, sendo que seis, tratam de políticas e ações afirmativas num contexto de democratização e educação como bem público. Nesse sentido,

Educação democrática implica expansão da cobertura, justiça social, qualidade científica e relevância social para todos. São exigências éticas e políticas que se requerem da educação pública, além de técnicas e científicas, pois são essenciais à construção de sujeitos sociais, à consolidação da sociedade democrática e dos processos de inclusão socioeconômica (DIAS SOBRINHO, 2013, p. 115).

Também se apresentam as temáticas de inclusão de sujeitos: alunos oriundos de escolas públicas, alunos com deficiências diversas e alunos com deficiência auditiva com abordagem de tecnologias de apoio (assistivas) à mediação técnico-pedagógica para o sujeito com deficiência auditiva; os impactos da presença de negros e indígenas que reivindicam espaços nas universidades.

Quanto às estratégias de enfrentamento ao problema da exclusão, os artigos tratam das ações afirmativas. Uma pesquisa aponta para a predominância da percepção de que as desigualdades de classe são mais relevantes do que as desigualdades raciais entre os articuladores das ações afirmativas 
no nível local, seja nos conselhos universitários, seja nas assembleias legislativas (DAFLON; FERES JÚNIOR; CAMPOS, 2013).

Quatro artigos abordaram o tema da permanência. Em sua análise, identificou-se que os pesquisadores correlacionaram outros aspectos que devem ser pertinentes à análise do tema da permanência. Os estudos indicam que as políticas educacionais, principalmente as de acesso, têm que estar na pauta de discussão sobre a permanência.

Para que o sistema de ensino superior no nosso país deixe de ser o Destino exclusivo da elite para se tornar uma Escolha possível para qualquer cidadão, seria importante rever nossas representações e práticas do que deva ser esse sistema e o seu funcionamento. Um sistema de ensino superior mais justo e aberto, mais inclusivo e mais coesivo. (BARBOSA, 2015, p. 277).

Outros pontos importantes são a necessidade de olhar sobre a gestão das IES e o processo de democratização da educação no país. Partindo de uma sociedade mais justa e que colocasse os estudantes nas mesmas condições de acesso, o ensino superior apresentaria igualdade de oportunidades de continuidade dos estudos e passaria a ser menos elitista.

\section{Democratização}

Foram analisados sete artigos que tratam da democratização e a colocam no contexto de uma expansão de natureza privada e do acesso à educação superior. As pesquisas abordam temas diversos: a educação como bem público e a qualidade da educação; o acesso das classes populares e a concessão de condições de privilégios a determinado(s) grupo(s), sucesso acadêmico, protagonismo dos desenhos curriculares e assistência estudantil.

Há o reconhecimento de um passivo educacional. Todavia, evidencia-se também que a educação não pode reduzir-se ao papel de estar a serviço do mercado, e tampouco a democratização pode se limitar à expansão quantitativa do acesso. Amplia-se a compreensão da democratização na perspectiva do sucesso acadêmico, assistência estudantil e protagonismo do currículo. Verificou-se que os entendimentos acerca do sucesso acadêmico tomam direções distintas, sobretudo em razão das visões de mundo que os sujeitos que 
A produção de conhecimentos sobre Educação Superior no Brasil em artigos publicados entre 2008 e 2018

os empregam compartilham e que thes são, portanto, subjacentes. Isso não importa, contudo, dizer que essas distintas direções sejam incompatíveis entre si (USTÁRROZ; FELDMAN; MOROSINI, 2017).

Dentro das análises aqui realizadas, três categorias apareceram em comum tanto nas produções acadêmicas quanto nos documentos resultantes das Conferências Nacionais de Educação (CONAEs) e nos PNEs: a integralização curricular, a vida acadêmica e a cidadania. A categoria competência não foi diretamente contemplada, o que abre espaço para reflexões (MOROSINI, $2017)$.

A política da assistência estudantil encontra-se no dilema de assegurar a permanência de estudantes das classes populares na universidade, enquanto a democratização do ensino superior ocorre de forma a provocar o desmonte da política pública de educação. $\bigcirc$ referido desmonte da política de educação superior é mediado por uma expansão e democratização que se materializam por iniciativas que mercantilizam e precarizam o ensino, tais como o FIES, o ProUni e a EaD (ARAÚjO, 2017).

\section{Considerações Finais}

Para se entender os achados deste estudo, é necessário demarcar que a maior parte dos artigos selecionados se concentra no período de 2015 a 2017, em publicações de periódicos brasileiros, com predomínio daqueles que têm escopo na educação superior - Revista Internacional de Educação Superior e Avaliação: Revista da Avaliação da Educação Superior. A produção de conhecimentos elegeu as instituições de ensino superior privadas como campo empírico mais incidente. De forma geral, os trabalhos apresentam como, traço comum, a utilização de abordagens metodológicas qualitativas.

A temática mais recorrente foram as políticas educacionais, principalmente, as de diversificação e expansão da educação superior. Evidencia-se a reconfiguração do papel do Estado como agente fomentador, regulador e avaliador. Critica-se a perda da autonomia do Estado na constituição e execução de políticas em detrimento das interferências e interesses de organismos multilaterais. A produção de conhecimentos sobre educação superior retrata um cenário de educação superior no Brasil, influenciado por movimentos globais do capitalismo, sob viés neoliberal, estimulado por organismos multilaterais, 
que impulsionam uma expansão mercantilizada, diversificada, privada e elitizada. Sinaliza, igualmente, que a educação superior, no Brasil, tem sido cada vez tratada como um bem mercantil privado a serviço do mercado de trabalho. Os movimentos de massificação são providos por IES com fins lucrativos, com a EaD como modalidade predominante. A propósito, percebe-se a necessidade de mais estudos que avaliem a qualidade da formação em nível superior oferecida por instituições privadas de educação a distância.

No cômputo geral, a partir do destaque do macrocenário, identifica-se um debate homogêneo, caracterizado pela recorrência e transversalidade de temáticas e conteúdos analisados e coincidência de abordagens e perspectivas de análise.

Por fim, identifica-se a ausência de estudos que estabeleçam relações entre o mundo do trabalho, profissões e formação acadêmica, a partir de referenciais teórico-metodológicos de diferentes campos de conhecimentos, que apontem para outras possíveis perspectivas de cenários na educação superior brasileira na contemporaneidade.

\section{Nota}

1 Não totalizam 130, pois, em duas instituições, não havia dados suficientes para segmentá-las entres as três categorias definidas no estudo.

\section{Referências}

AGUIAR, Maria da Conceição Carrilho de. Um olhar sobre desafios da gestão didático-pedagógica no ensino superior. Pro-Posições, Campinas, v. 27, n. 3, p. 221-236, dez. 2016.

ALONSO, Kátia Morosov. A expansão do ensino superior no Brasil e a EaD: dinâmicas e lugares. Educação \& Sociedade, Campinas, v. 31 , n. 113, p. 131 19-1335, out./dez. 2010.

ARAÚJO, Maria Luciene da Silva. Reconfiguração do ensino superior brasileiro: direito ou desmonte? Revista Internacional de Educação Superior, Campinas, v. 3, n. 3, p. 645 $677,2017$.

AZEVEDO, Mário Luiz Nunes de. Transnacionalização e mercadorização da educação superior: examinando alguns efeitos colaterais do capitalismo acadêmico (sem riscos) 
A produção de conhecimentos sobre Educação Superior no Brasil em artigos publicados entre 2008 e 2018

no Brasil - a expansão provado-mercantil. Revista Internacional de Educação Superior, Campinas, v. 1, n. 1, p. 86-102, jul./set. 2015.

BARBOSA, Maria Ligia de Oliveira. Destinos, escolhas e a democratização do ensino superior. Revista Política e Sociedade, Florianópolis, v. 14, n. 31 , p. 256-282, set./dez. 2015.

BORGES, Maria Célia; AQUINO, Orlando Fernandez. Educação superior no Brasil e as políticas de expansão de vagas do REUNI: avanços e controvérsias. Revista Educação: Teoria e Prática, Rio Claro, v. 22, n. 39, p. 117-138, jan./abr. 2012.

CASTRO, Alda Maria Duarte Araújo; PEREIRA, Raphael Lacerda de Alencar. Contratualização no ensino superior: um estudo à luz da nova gestão pública. Acta Scientiarum Education, Maringá, v. 36, n. 2, p. 287-296, jul./dez. 2014.

CHAVES, Vera Lúcia Jacob; AMARAL, Nelson Cardoso. A educação superior no Brasil: os desafios da expansão e do financiamento e comparações com outros países. Revista Educação em Questão, Natal, v. 51 , n. 37, p. 95-120, jan./abr. 2015.

COSTA, Nadja Lima; COSTA E SILVA, Ana Maria. Qualidade social e políticas para a Educação Superior no Brasil. Revista de Estudios e Investigación en Psicología y Educación, Coruña, n. 12, p. 6-10, 2015.

22 CUNHA, Maria Isabel da. Qualidade da educação superior e a tensão entre democratização e internacionalização na universidade brasileira. Avaliação, Campinas/Sorocaba, v. 22, n. 3, p. $817-832$, nov. 2017.

DAFLON, Verônica Toste; FERES JÚNIOR, João; CAMPOS, Luiz Augusto. Ações afirmativas raciais no ensino superior público brasileiro: um panorama analítico. Cadernos de Pesquisa, São Paulo, v. 43, n. 148, p. 302-327, abr. 2013.

DIAS, Rafael; SERAFIM, Milena. Comentários sobre as transformações recentes na universidade pública brasileira. Avaliação, Campinas/Sorocaba, v. 20, n. 2, 2015.

DIAS SOBRINHO, José; BRITO, Márcia Regina Ferreira de. La educación superior en Brasil: principales tendencias y desafios. Avaliação, Campinas/Sorocaba, v. 13, n. 2, p. 487507 , jul. 2008.

DIAS SOBRINHO, José. Educação superior: bem público, equidade e democratização. Avaliação, Campinas/Sorocaba v. 18, n. 1, p. 107-126, mar. 2013.

DIAS SOBRINHO, José. Universidade e novos modos de produção, circulação e aplicação do conhecimento. Avaliação, Campinas/Sorocaba, v. 19, n. 3, p. 643-662, nov. 2014.

DIAS SOBRINHO, José. Universidade fraturada: reflexões sobre conhecimento e responsabilidade social. Avaliação, Campinas/Sorocaba, v. 20, n. 3, p. 581-601, nov. 2015. 
FÁVERO, Altair Alberto; BECHI, Diego. O financiamento da educação superior no limiar do século XXI: o caminho da mercantilização da educação. Revista Internacional de Educação Superior, Campinas, v. 3, n. 1, p. 90-113, jan./abr. 2017.

FÁVERO, Maria de Lourdes de Albuquerque; SGUISSARDI, Valdemar. Quantidade/ Qualidade e Educação Superior. Revista Educação em Questão, Natal, v. 42, n. 28, p. 61-88, jan./abr. 2012.

FRANKLIN, Luiza Amália; ZUIN, Débora Carneiro; EMMENDOERfER, Magnus Luiz. Processo de internacionalização do ensino superior e mobilidade acadêmica: implicações para a gestão universitária no Brasil. Revista Internacional de Educação Superior, Campinas, v. 4, n. 1, p. 130-151, out. 2018.

GOMES, Alfredo Macedo; MORAES, Karine Nunes de. Educação superior no Brasil contemporâneo: transição para um sistema de massa. Educação e Sociedade, Campinas, v. 33, n. 118 , p. 171-190, jan./mar. 2012.

HOFFMANN, Celina; ZANINI, Roselaine Ruviaro; CORRÊA, Ângela Cristina; SILUK, Julio Cezar Mairesse; SCHUCH JÚNIOR, Vitor Francisco; ÁVILA, Lucas Veiga. O desempenho das universidades brasileiras na perspectiva do Índice Geral de Cursos (IGC). Educação e Pesquisa, São Paulo, v. 40, n. 3, p. 651-666, 2014.

JUNG, Hildegard Susana; CAUDURO, Tharles Gabriele; SUDBRACK, Edite Maria. O Plano Nacional de Educação como articulador da democratização do acesso à universidade e empoderamento da classe trabalhadora. Revista Internacional da Educação Superior, Campinas, v. 2, n. 2, p. 257-273, maio/ago. 2016.

LIMA, Licínio Carlos Viana da Silva; AZEVEDO, Mário Luiz Neves de; CATANI, Afrânio Mendes. O Processo de Bolonha, a avaliação da educação superior e algumas considerações sobre a Universidade Nova. Avaliação, Campinas/Sorocaba, v. 13, n. 1, p. 7-36, mar. 2008.

LIMA, Telma Cristiane Sasso de; MIOTO, Regina Célia Tamaso. Procedimentos metodológicos na construção do conhecimento científico: a pesquisa bibliográfica. Revista Katálysis, Florianópolis, v. 10, p. 37-45, 2007 (número especial).

MARQUES, Waldemar. Expansão e oligopolização da Educação Superior no Brasil. Avaliação, Campinas; Sorocaba, v. 18, n. 1, p. 69-83, mar. 2013.

MAUÉS, Olgaíses Cabral; SOUZA, Michele Borges de Souza. A transnacionalização e a expansão da educação superior. Revista Educação em Questão, Natal, v. 56, n. 47, p. 151-173, jan./abr. 2018.

MELO, Pedro Antônio de; MELO, Michelle Bianchini de; NUNES, Rogério da Silva. A Educação a Distância como política de Expansão e Interiorização da Educação Superior 
A produção de conhecimentos sobre Educação Superior no Brasil em artigos publicados entre 2008 e 2018

no Brasil. Revista de Ciências da Administração, Florianópolis, v. 1 1 , n. 24, p. 278-304, maio/ago. 2009.

MINTO, Lalo Watanabe. Educação Superior no PNE (2014-2024): apontamentos sobre as relações público-privadas. Revista Brasileira de Educação, Campinas, v. 23, e2300 1 1, p. 1-17, 2018.

MOROSINI, Marília Costa. Qualidade da educação superior e contextos emergentes. Avaliação, Campinas/Sorocaba, v. 19, n. 2, 2014.

MOROSINI, Marília Costa; CORTE, Marilene Gabriel Dalla. Teses e realidades no contexto da internacionalização da Educação Superior no Brasil. Revista Educação em Questão, Natal, v. 56, n. 57, p. 97-120, jan./mar. 2018.

MOURA, Bruno Azevedo; MOURA, Leides Barroso Azevedo. Ranqueamento de universidades: reflexões acerca da construção de reconhecimento institucional. Acta Scientiarum Education, Maringá, v. 35, n. 2, p. $213-222,2013$.

PAULA, Alisson Slider do Nascimento; LIMA, Kátia Regina Rodrigues; LIMA, EMMANOEL, Ferreira; COSTA, Frederico Jorge Ferreira. A política de educação superior brasileira e seus nexos com o capital: o PNE (2014-2024) em foco. Revista Internacional da Educação Superior, Campinas, v. 4, n. 2, p. 330-346, maio/ago. 2017.

24 PAULA, Alisson Slider do Nascimento; COSTA, Frederico Jorge Ferreira; LIMA, Kátia Regina Rodrigues. A condicionalidade do Estado avaliador e suas implicações na avaliação e a expansão mercantilizada da educação superior brasileira. Revista Internacional de Educação Superior, Campinas, v. 4, n. 2, p. 330-346, fev. 2018.

PEREIRA, Elisabete Monteiro de Aguiar. A universidade da modernidade nos tempos atuais. Avaliação, Campinas/Sorocaba, v. 14, n. 1, p. 29-52, mar. 2009.

PIMENTA, Alexandre Marinho. A EaD como renovação do mercado educacional brasileiro do nível superior. Revista Internacional de Educação Superior, Campinas, v. 3, n. 2, p. 308-321, 2017.

PIZZANI, Luciana; SILVA, Rosemary Cristina da; BELLO, Suzelei Faria; HAYASHI, Maria Cristina Piumbato Innocentini. A arte da pesquisa bibliográfica na busca do conhecimento. Revista Digital de Biblioteconomia e Ciência da Informação, Campinas, v. 10, n. 1, p. 53-66, jul./dez. 2012.

QUEIROZ, Fernanda Cristina Barbosa Pereira; QUEIROZ, Jamerson Viegas; VASCONCELOS, Natalia Veloso Caldas de; FURUKAVA, Marciano; HÉKIS, Hélio Roberto; PEREIRA, Flávia Aparecida Barbosa. Transformações no ensino superior brasileiro: análise das instituições privadas de ensino superior no compasso com as políticas de Estado. Ensaio, Rio de Janeiro, v. 21, n. 79 , p. 349-370, abr./jun. 2013. 
SAMPAIO, Helena. Diversidade e diferenciação no ensino superior no Brasil: conceitos para discussão. Revista Brasileira de Ciências Sociais, v. 29, n. 84, 2014.

SEGENREICH, Stella Cecilia Duarte; CASTANHEIRA, Antonio Mauricio. Expansão, privatização e diferenciação da educação superior no Brasil pós-LDBEN/96: evidências e tendências. Ensaio: avaliação e políticas públicas em educação, Rio de Janeiro, v. 17, n. 62, 2009.

SEVERINO, Antônio Joaquim. $\bigcirc$ ensino superior brasileiro: novas configurações e velhos desafios. Educar em Revista, Curitiba, v. 24, n. 31 , p. 73-89, 2008.

SILVA, Matheus Castro da. O ser e o não ser da universidade pública: o público e o privado em questão na educação superior brasileira. Revista HISTEDBR On-line, Campinas, v. 15, n. 63, p. 172-188, 2015.

SILVA, Rosa Maria Segalla; AMAURO, Nicéa Quintino; SOUZA, Paulo Vitor Teodoro; RODRIGUES FILHO, Guimes. Democratização do ensino superior: no contexto da educação brasileira. Revista Ibero-Americana de Estudos em Educação, Araraquara, v. 12, n. 1, p. 294-312, jan./mar. 2017.

USTÁRROZ, Elisa; FELDMAN, Sergio Alberto; MOROSINI, Marilia Costa. Democratização da educação superior brasileira: do acesso ao compromisso com o sucesso acadêmico. Revista Internacional de Educação Superior, Campinas, v. 3, n. 3, p. 538-562, set./dez. 2017.

WIELEWICKI, Hamilton de Godoy; OLIVEIRA, Marlize Rubin. Internacionalização da Educação Superior: Processo de Bolonha. Ensaio, Rio de Janeiro, v. 18, n. 67, p. 215 234, abr./jun. 2010.

Prof. Dr. Artur Eugênio Jacobus

Universidade do Vale do Rio dos Sinos (Brasil) Unidade Acadêmica de Pesquisa e Pós-Graduação Programa de Pós-Graduação em Gestão Educacional Grupo de Pesquisa Democratização, Inclusão e Gestão na Educação Superior ORCID ID: https:/ / orcid.org/0000-000 1-5471-9676 E-mail: jacobus@unisinos.br 
Prof. Dr. Ricardo Ferreira Vitelli Universidade do Vale do Rio dos Sinos (Brasil) Unidade Acadêmica de Graduação Grupo de Pesquisa Evasão escolar, gestão e formação de recursos humanos em escolas públicas de ensino médio no município de São Leopoldo-RS ORCID ID: https:/ / orcid.org/0000-0002-8023-9 163 E-mail: vitelli@unisinos.br

Profa. Dra. Rosangela Fritsch Universidade do Vale do Rio dos Sinos (Brasil) Unidade Acadêmica de Pesquisa e Pós-Graduação Programa de Pós-Graduação em Educação e Mestrado Profissional em Gestão Educacional

Grupo de Pesquisa Evasão escolar, gestão e formação de recursos humanos em escolas públicas de ensino médio no município de São Leopoldo (Rio Grande do Sul) ORCID ID: https:/ / orcid.org/0000-0002-0630-3649 E-mail: rosangelaf@unisinos.br Recebido 18 mar. 2019 Aceito 17 maio 2019 